\title{
Willingness To Pay Masyarakat dalam Mengurangi Dampak Sampah Rumah Tangga \\ ${ }^{1}$ Sulistya Rini Pratiwi, Jurusan Ekonomi Pembangunan, Universitas Borneo Tarakan, Indonesia \\ ${ }^{2}$ Kasmawati, Jurusan Ekonomi Pembangunan, Universitas Borneo Tarakan, Indonesia
}

\section{Informasi Naskah}

Submitted:6 Oktober 2019

Revision: 6 November 2019

Accepted: 8 November 2019

\section{Kata Kunci:}

WTP, Pengelolaan Sampah, Sampah Rumah Tangga, Perbaikan Lingkungan

\begin{abstract}
The purpose of this study is to analyze the willingness to pay in the City of Tarakan. Its aim focuses on reducing the negative impact of waste and determine how much influence the value of the willingness to pay the community in reducing the harmful effects of waste in the City of Tarakan. The type of data used in the study is primary data and secondary data. The research location was carried out in four sub-districts in Tarakan City, the research took 30 days to distribute questionnaires, and 400 respondents were received in four sub-districts. City of Tarakan in the amount of Rp. 16575. Simultaneous test results showed that the independent variables namely age, sex, level of education, number of family members and income affect WTP (willingness to pay the community).
\end{abstract}

\begin{abstract}
Abstrak
Tujuan penelitian ini adalah untuk menganalisi kesediaan membayar masyarakat dalam mengurangi dampak negatif dari sampah di Kota Tarakan dan mengetahui seberapa besar pengaruh nilai kesediaan membayar masyarakat dalam mengurangi dampak negatif dari sampah di Kota Tarakan. Jenis data yang digunakan dalam penelitian yaitu data primer dan data sekunder. Lokasi penelitian dilaksanakan di empat kecamatan yang ada di Kota Tarakan, waktu penelitian selama 30 hari untuk penyebaran kuesioner, dan responden yang di dapat sebanyak 400 responden di empatkecamatan. Berdasarkan hasil penelitian, didapatkan kontribusi WTP (kesediaan kesediaan membayar) dalam mengurangi dampak negatif sampah di Kota Tarakan sebesar Rp. 16.575. Hasil uji simultan, menunjukkan bahwa variabel independen yaitu umur, jenis kelamin, tingkat pendidikan, jumlah anggota keluarga dan pendapatan berpengaruh terhadap WTP (kesediaan membayar masyarakat) dan berdasarkan hasil uji F statistik menunjukkan bahwa variabel pendapatan berpengaruh signifikan terhadap WTP (kesediaan kesediaan membayar.
\end{abstract}




\section{PENDAHULUAN}

Eksternalitas timbul pada dasarnya karena aktivitas manusia yang tidak mengikuti prinsip-prinsip ekonomi yang berwawasan lingkungan(Gillingham, 2011). Dalam pandangan ekonomi, eksternalitas dan ketidakefisienan timbul karena salah satu atau lebih dari prinsipprinsip alokasi sumber daya yang efesien tidak terpenuhi. Karakteristik barang atau sumber daya publik, ketidaksempurnaan pasar kegagalan pemerintah merupakan keadaan-kedaan dimana unsur hak pemikiran atau pengusahaan sumber daya (property rights) tidak terpenuhi(Frischmann, Marciano, \& Ramello, 2019). Sejauh semua faktor ini tidak ditangani dengan baik, maka ekternalitas dan keefesienan ini tidakbisadihindari.Berbagai pendapat mengemukakan teorinya tentang pengertian eksternalitas. Eksternalitas terjadi ketika aktivitas suatu satu kesatuan mempengaruhi kesejahteraan kesatuan yang lain yang terjadi diluar mekanisme pasar (non marketmechanism)(Bourne, 2019; Liebowitz \& Margolis, 1995; Read \& Read, 2016).

Tidak seperti pengaruh yang ditrasmisikan melalui mekanisme harga pasar, eksternalitas dapat mempengaruhi efesiensi ekonomi. Eksternalitas terjadi bila satu aktivitas pelaku ekonomi baik produksi maupun konsumsi mempengaruhi kesejateraan pelaku ekonomi lain peristiwa yang ada terjadi di luar mekanisme pasar(Commision, 2014; Grossman, 1990).Sehingga terjadi eksternalitas maka private choices oleh konsumen dan produsen dalam private markets umumnya tidak menghasilkan sesuatu secara ekonomi efisien. Berdasarkan pada pemahaman di atas dapat dijelaskan bahwadalam prespektif teoritis, eksternalitas terjadi karena adanya perbedaan antara marginal social dan private cost suatu barang. Dalam kasus kerusakan lingkungan menimbulkan negative eksternality karena tidak adanya unsur biaya tambahan dalam bentuk social cost yang masuk dalam komponen harga barang akhir.Oleh karena itu diperlukan goverment intervention dalam bentuk penetapan pajak atau subsidi guna untuk mengoreksi dampak-dampak dari eksternalitas ( Rietveld\& Nijkamp, 2000; Smith, 2008; Verhoef et al., 2009; David et al, 2017).

Ekternalitas adalah dampak dari suatu tindakan pihak tertentu terhadap pihak lain baik dampak yang menguntungkan maupun dampak yang merugikan. Ekternalitas terjadi apabila tindakan seseorang menimbulkan dampak terhadap orang lain atau sekelompok orang tanpa ada konpensasi apapun sehingga timbul inefisiensi dalam alokasi faktor produksi.Ekternalitas timbul pada dasarnya karena aktivitas manusia yang tidak mengikuti prinsip-prinsip ekonomi yang berwawasan lingkungan (Ziolo et al., 2019).Ekternalitas juga dapat didefinisikan sebagai biaya ekonomi atau manfaat yang merupakan produk sampingan dari kegiatan ekonomi tetapi yang dialokasikan di luar sistem pasar. Ini berarti ekternalitas tidak memiliki insentif untuk mempertimbangkan biaya biayaeksternal atau manfaat yang dihasilkan.Salah satu masalah eksternalitas yang akan dibahas dalam penelitian menyangkut masalah sampah.

Sampah merupakan permasalahan utama di negara kita yang masih belum dapat terselesaikan dengan baik. Menurut data Lingkungan Hidup Indonesia tahun 2016 jumlah peningkatan timbulan sampah di Indonesia telah mencapai 175.000 ton/hari atau setara 65 juta ton/hari (KLH, 2017). Menurut Badan Lingkungan Hidup (BLH) tantangan terbesar pengelolaan sampah adalah penanganan sampah plastik yang tidak ramah lingkungan. Berdasarkan hasil studi yang dilakukan di beberapa kota tahun 2012, pola pengelolaan sampah di Indonesia sebagi berikut : Diangkut danditimbun di TPA (69\%), dikubur (10\%), dikompos dan didaur ulang (7\%), dibakar (5\%), dan sisanya tidak terkelola (7\%) (BLH, 2016).

Timbulan sampah padat tidak dapat dihentikan, akan tetapi harus dikelola, dikurangi atau diminimalisasi secara baik. Menurut Undang-Undang Nomor 18 Tahun 2008 tentang Pengelolaan Sampah Bab I Pasal I ; dinyatakan bahwa Pengelolaan sampah adalah kegiatan yang sistematis, menyeluruh, dan berkesi-nambungan yang meliputi pengurangan dan penanganan sampah. Di dalam Undang-Undang tersebut disebutkan bahwa setiap orang dalam pengelolaan sampah rumah tangga dan sampah sejenis sampah rumah tangga wajib mengungurangi dan menangani sampah dengan cara yang berwawasan lingkungan.

Sistem Pengelolaan Sampah Secara Terpadu merupakan pendekatan sistem yang patut dijadikan sebagai solusi pemecahan masalah persampahan. Pengelolaan sampah teRpadu adalah kegiatan yang sistematis, menyeluruh, dan berkesinambungan yang meliputi pengurangan dan penanganan sampah (UU Nomor 18 Tentang Pengelolaan Sampah, 2008). 
Sistem pengelolaan sampah terpadu tersebut berarti paling tidak mengkombinasikan pendekatan pengurangan sumber sampah, daur ulang \& guna ulang, pengkomposan, dan pembuangan akhir. Sistem pengelolaa yang digunakan adalah sistem zero waste.

Zero Waste adalah mulai dari suatu proses produksi sampai berakhirnya suatu proses produksi dapat meminimalisir terjadinya sampah. Konsep Zero Waste ini salah satunya dengan menerapkan prinsip 3R (Reduce, Reuse, Recycle). Pemikiran konsep zero waste adalah pendekatan serta penerapan sistem dan teknologi pengolahan sampah perkotaan skala individual dan skala kawasan secara terpadu dengan sasaran untuk dapat mengurangi volume sampah seminimal mungkin(Centemeri, 2019; Nizar, Munir, \& Munawar, 2013). Konsep 3R adalah merupakan dasar dari berbagai usaha untuk mengurangi limbah sampah dan mengoptimalkan proses produksi sampah (Affandy et al., 2015).

Zero waste mencakup proses untuk memaksimalkan recycling, meminimalisasi limbah, mengefektifkan konsumsi dan memastikan suatu produk dapat digunakan kembali, atau minimal didaur ulang sehingga dapat direduksi oleh alam. Tapi konsep zero waste ataupun dalam arti harfiahnya mustahil terealisasi. Karena secara umum semua proses akan menghasilkan zat sisa. Sehingga yang paling diharapkan dari prinsip ini adalah limbah yang dihasilkan daspat direduksi secara mudah dan cepat. Pada konsep Zero Waste limbah sudah diminimalisasi, ditekan sedemikian mungkin pada seluruh tahapan produksi, sejak awal proses produksi hingga akhirnya produk tersebut selesai digunakan sehingga limbah yang dihasilkan benar-benar mendekati nilai nol(Human, 2019). Produk yang dihasilkan pun dipastikan dapat digunakan kembali, diperbaiki atau didaur ulang kembali dengan limbah yang sangat minim atau mendekati nol. Zero waste mencakup seluruh sistem pada suatu proses produksi ataupunaktifitas.Zero waste mencakup seluruh kegiatan manusia. Sehingga semua bidang kehidupan dan segala aktifitas manusia dapat menerapkan prinsip ini. Manfaat keberlanjutan ekonomi, daya dukung lingkungan, dan daya dukung sosial.

Selanjutnya, secara umum, nilai ekonomi didefinisikan sebagai pengukuran jumlah maksimum seseorang ingin mengorbankan barang dan untuk memperoleh barang dan jasa lainnya. Secara formal, konsep ini disebut keinginan membayar atau Willingnesss To Pay (WTP) seseorang terhadap barang dan jasa yang dihasilkan.Dengan menggunakan pengukuran ini, nilai ekologis ekosistem bisa diterjemahkan ke dalam bahasa ekonomi dengan mengukur nilai moneter barang dan jasa. Keinginan membayar juga dapat diukur dalam bentuk kenaikan pendapatan yang menyebabkan seseorang berada dalam posisiindefferentnterhadap perubahan eksogenous(Clark et al., 2006). Perubahan eksogenous ini bisa terjadi karena perubahan harga misalnya : sumber daya yang langka atau karena perubahan kualitas sumber daya. Dengan demikian konsep WTP ini terkait dengan konsep Compensating Variation dan Equivalent Variation dalam teori permintaan. WTP dapat juga diartikan sebagai jumlah maksimal yang seseorang bersedia bayarkan untuk menghindari terjadinya penurunan terhadap sesuatu.

Penelitian ini mendasarkan pemikirannya berdasarkan hasil penelitian yang dilakukanmengenai analisis kesediaan membayar iuran kebersihan terhadap kepuasan masyarakat di lingkungan kelurahan Labuh baru sebesar Rp. 5000,00 sampai dengan Rp. 30.000,00(Handayani, Chalid, \& Iyan, 2015). Kesediaan membayar iuran kebersihan oleh masyarakat dapat diketahui bahwa total kesediaan membayar WTP adalah sebesar Rp. 63.251.285,72. Dengan rata-rata kesediaan membayar per bualan adalah sebesar Rp. 13.384,00 per KK. Hasil dari pengujian serempak faktor pendapatan, berat sampah rumah tangga menujukkan bahwa faktor pendapatan yang dominan mempengaruhi kesediaan membayar. Semakin tinggi pendapatan maka semakin tinggi pula kesediaan membayar iurankebersihan(Barwick, Li, Rao, \& Zahur, 2018; Carlsson \& Johansson-Stenman, 2000; Yang, Ding, Liu, Xu, \& Nicholas, 2018). Beberapa penelitian menyebut-kan bahwa nilai rata-rata WTP masyarakat dalam upaya peningkatan kualitas lingkungan akibat sampah adalah besar(Malinauskaite et al., 2017; OECD, 2008). Nilai WTP meningkat sejalan dengan informasi yang mereka dapatkan (Ferronato \& Torretta, 2019; Yoada, Chirawurah, \& Adongo, 2014).

\section{METODOLOGI PENELITIAN}

Analisis data yang digunakan, yaitu analisis kuantitatif. Analisis data kuantitatif merupakan 
analisis yang menggunakan angka - angka dengan perhitungan statistik dan beberapa alat analisis. Analisis kuantitatif digunakan untuk mengetahui faktor - faktor yang beRpengaruh terhadap willingness to pay atau kesediaan membayar responden terhadap pengelolaan sampah di Kota Tarakan. Ada sebanyak 400 responden yang tersebar di 4 (empat) kecamatan di Kota Tarakan. Dalam penelitian ini, nilai WTP masyarakat mengenai tempat pengelolaan sampah terpadu diduga dengan menggunakan metode Contingent Valuation Method. Pelaksanaan CVM dalam penelitian ini menggunakan pendekatan(Desvousges, Mathews, \& Train, 2012; Hoevenagel, 1996), adalah sebagai berikut:

1. Membangun Pasar Hipotetis (Setting up The HypotheticalMarket).

2. Mendapatkan Nilai WTP (ObtaningBids).

3. Menghitung Dugaan Rata-Rata Nilai WTP (Estimating MeanWTP).

4. Menjumlahkan Data (AgregatingData).

\section{HASIL DAN PEMBAHASAN}

\section{Karakteristik Responden}

Responden dalam penelitian ini adalah masyarakat Kota Tarakan yang dalam hal ini adalah kepala keluarga atau seseorang yang bertanggung jawab dalam memenuhi kebutuhan rumah tangga. Jumlah responden dalam penelitian ini adalah 400 responden dimana terdapat 100 responden ditiap-tiap Kecamatan yang ada di Kota Tarakan. Karakteristik responden ini terdiri dari beberapa aspek adalah : kesediaan membayar (WTP), usia, jenis kelamin, pendapatan, jumlah anggota keluarga yang di tanggungi, dan tingkat pendidikan.

\section{Tabel 1.}

Demografi Dan Karakteristik Responden ( $\mathrm{N}=400)$

\begin{tabular}{lll}
\hline Karakteristik & Mayoritas & Persentase \\
\hline Jenis Kelamin & Laki-Laki & 84 \\
Umur & Perempuan & 16 \\
& $<30$ & 18 \\
\multirow{3}{*}{ Pendidikan } & $31-40$ & 27 \\
JumlahAnggotaKeluarga & $>41$ & 55 \\
& <SMA & 29 \\
Pendapatan & >SMA & 71 \\
& $4-5$ & 34 \\
WTP & <RP2.000.000 & 66 \\
& RP2.100.000-RP 3.000.000 & 24 \\
& $>$ RP 3.100.000 & 50 \\
& 0 & 26 \\
& <Rp 10.000 & 4 \\
& Rp 11.000-Rp 20.000 & 3 \\
\hline
\end{tabular}

Sumber: Data Primer, 2019

Hasil dari penjumlahan WTP yang di peroleh yaitu sebesar Rp. 16.575. dengan jumlah yang di peroleh masyarakat bersedia membayar dalam mengurangi dampak sampah di Kota Tarakan. Nilai lebih tinggi dari nilai yang seharusnya dibayarkan (Rp. 15.000). Hal ini menunjukkan bahwa tingkat kesadaran masyarakat terhadap peningkatan kualitas lingkungan akibat sampah rumah tangga adalah tinggi. Beberapa penelitian mendapatkan hasil yang samadengan studi ini (Malinauskaite et al., 2017)

Hasil analisis regresi linier berganda dengan pendekatan Ordinary Least Square (OLS) terhadap kesediaan masyarakat dalam mengurangi dampak sampah di Kota Tarakan dan variabel yang mempengaruhinya (umur, jenis kelamin, tingkat penidikan, jumlah anggota keluarga, dan pendapatan) ditunjukan oleh persamaan regresi berganda sebagai berikut: 
Tabel 2.

Hasil Analisis Regresi

\begin{tabular}{ccccc}
\hline Variable & Coefficient & t-Statistic & Prob. & Keterangan \\
\hline Umur & 0.857443 & 0.043189 & 0.9656 & Tidak Signifikan \\
Jenis Kelamin & -302.4937 & -0.640563 & 0.5222 & Tidak Signifikan \\
Tingkat Pendidikan & -346.0025 & -1.907641 & 0.0572 & Tidak Signifikan \\
$\begin{array}{c}\text { Jumlah Anggota } \\
\text { Keluarga }\end{array}$ & 68.93981 & 0.381814 & 0.7028 & Tidak Signifikan \\
Pendapatan & 0.005514 & 17.45671 & 0.0000 & Signifikan \\
\hline
\end{tabular}

Sumber: Data Primer diolah, 2019

Secara keseluruhan, variabel pada model tidak berpengaruh signifikan terhadap besarnya WTP. Hanya variabel Pendapatan saja yang berpengaruh signifikan(Barwick et al., 2018; Yang et al., 2018)Seiring bertambahnya umur responden tidak berbanding lurus dengan peningkatan nilai WTP. Berdasarkan hasil survey, hal ini disebabkan karena rata-rata pada usia tua, responden lebih memilih fokus pada pembiayaan kesehatan, sehingga cenderung mengabaikan kondisi lingkungan akibat sampah. Hal ini senada dengan hubungan variabel Pendidikan yang negatif. Pendidikan formal ternyata tidak cukup meningkatkan kesadaran masyarakat akan dampak dan memperbaiki kualitas lingkungan(Ferronato \& Torretta, 2019; Yoada et al., 2014).

Terdapat perbedaan besarnya nilai WTP yang dipilih responden pada jenis kelamin lakilaki dan perempuan. Responden berjenis kelamin laki-laki cenderung memilih skenario WTP lebih tinggi dari pada perempuan. Atau laki-laki memiliki nilai WTP lebih besar dari pada perempuan. Hal ini bisa jadi dikarenakan, responden berjenis laki-laki mayoritas adalah kepala rumah tangga dan atau yang memiliki penghasilan sendiri(Bobinac, Exel, Rutten, \& Brouwer, 2010). Sedangkan responden perempuan lebih banyak menerima uang dari suaminya.Banyaknya jumlah anggota keluarga ternyata tidak menyebab-kan nilai WTP responden menjadi rendah. Hal ini kemungkinan dikarenakan, jumlah anggota keluarga berdampak pada sampah rumah tangga pada anggota keluarga tersebut(Andrianto, Qurniati, \& Setiawan, 2016; Commission \& Communication, 2014; Maghdalena \& Widiastuti, 2014).

Besarnya koefesien determinasi $\left(\mathrm{R}^{2}\right)$ yang diperoleh adalah sebesar 0.624255 , hal ini menunjukkan bahwa variasi variabel independen yang digunakan dalam penelitian ini, yaitu umur, jenis kelamin, tingkat pendidikan, jumlah anggota keluarga, pekerjaan dan pendapatan hanyadapat menjelaskan variasi variabel WTP sebesar $62,42 \%$, sedangkan $37.58 \%$ dijelaskan oleh variabel lain yang tidak dimasukkan ke dalam model penelitian ini, karena variabel tersebut tidak dapat dimonetasi. Nilai R Square yang tinggi adalah baik tetapi apabila diperoleh nilai $R$ Square yang rendah bukanlah berarti hasil penelitian tersebut tidak baik(Gujarati, 2003). Hasil uji multikolinearitas dapat dilihat pada kolom Centered VIF. Berdasarkan tabel 3, hasilnya menunjukkan bahwa semua nilaiVIF Centered memiliki nilai yang lebih kecil dari 10 (VIF < 10). Hasil pengujian model regresi tersebut menunjukkan tidak adanya gejala multikolinearitas dalam model regresi. Hal ini menunjukkan bahwa semua variabel independen layak digunakan sebagai prediktor.

Hasil uji Breush-Godfrey dapat dilihat dari nilai prob. F(2,392) atau dapat disebut sebagai probabilitas $\mathrm{F}$ hitung. Berdasarkan tabel 4.12, hasilnya menunjukkan bahwa nilai Prob. $\mathrm{F}$ hitung lebih besar dari a $(0.4850>0,05)$. Hal ini menunjukkan bahwa tidak terjadi autokorelasi. Mendeteksi heteroskedastisitas dapat dianalisis dengan uji Glejser. Hasil uji heterokedastisitas dapat dilihat pada nilai Prob. F Statistik (F-hitung). Berdasarkan tabel 4.13, hasilnya menunjukkan Prob. $F$ hitung lebih besar dari tingkat $\alpha(0.0549>0,05)$. Hal ini menunjukkan tidak terjadi heteroskedastisitas. 
Tabel 3.

Varian Inflation Factor

\begin{tabular}{lccc}
\hline \multicolumn{1}{c}{ Variabel } & $\begin{array}{c}\text { Coefficient } \\
\text { Variance }\end{array}$ & Uncentered VIF & $\begin{array}{c}\text { Centered } \\
\text { VIF }\end{array}$ \\
\hline Umur & 394.1574 & 23.21210 & 1.063422 \\
Jenis Kelamin & 223001.7 & 28.54516 & 1.041435 \\
Tingkat Pendidikan & 32897.68 & 15.72677 & 2.465881 \\
Jumlah Anggota Keluarga & 32601.40 & 18.05602 & 1.067863 \\
Pendapatan & $9.98 \mathrm{E}-08$ & 25.85340 & 2.511357 \\
\hline
\end{tabular}

Sumber: Data Primer diolah, 2019

Tabel 4.

Hasil LM Test dan Glejser Test

\begin{tabular}{lcll}
\hline \multicolumn{3}{l}{ Breusch-Godfrey Serial Correlation LM Test } \\
\hline F-statistic & 0.725043 & Prob. F(2,392) & 0.4850 \\
Obs*R-squared & 1.474226 & Prob. Chi-Square(2) & 0.4785 \\
F-statistic & 2.187673 & Prob. F(5,394) & 0.0549 \\
Heteroskedasticity Test: Glejser & & \\
Obs*R-squared & 10.80497 & Prob. Chi-Square(5) & 0.0554 \\
Scaled explained SS & 14.05250 & Prob. Chi-Square(5) & 0.0153
\end{tabular}

Sumber: Data diolah, 2019

\section{KESIMPULAN DAN SARAN \\ Kesimpulan}

Berdasarkan hasil lapangan, menunjukkan bahwa besarnya nilai rata-rata WTP adalah Rp. 16.575. Nilai ini lebih besar dari nilai yang seharusnya dibayarkan oleh masyarakat, yaitu sebesar Rp.15.000. Hal ini menunjukkanbahwa masyarakat telah memiliki kesadaran lingkungan akibat dampak sampah. Selain itu, faktor yang paling berpengaruh signifikan terhadap besarnya nilai WTP masyarakat adalah Pendapatan.

\section{Saran}

Kurang informasi nonformal terkait dampak sampah rumah tangga menyebabkan kurangnya optimalnya kesadaran masyarakat. Sebaiknya perlu ada campur tangan pemerintah dalam program sosialisasi dampak dan pengelolaan sampah rumah tangga. Peningkatan pengetahuan masyarakat akan berdampak pada perilaku masyarakat terhadap perbaikan lingkungan akibat sampah.

\section{DAFTAR PUSTAKA}

Affandy, N. A., Isnaini, E., Yulianti, C. H., Sipil, J. T., Lamongan, U. I., Hukum, F., \& Lamongan, U. I. (2015). Peran Serta Masyarakat Dalam Pengelolaan. Seminar Nasional Sains Dan Teknologi Terapan III 2015, 803-814. Surabaya: Institut Teknologi Adhi Tama Surabaya. 
Andrianto, A., Qurniati, R., \& Setiawan, A. (2016). PENGARUH KARAKTERISTIK RUMAH TANGGA TERHADAP TINGKAT KEMISKINAN MASYARAKAT SEKITAR MANGROVE. Jurnal Sylva Lestari, 4(3), 107-113.

Barwick, P. J., Li, S., Rao, D., \& Zahur, N. Bin. (2018). Air Pollution, Health Spending and Willingness to Pay for Clean Air in China.

Bobinac, A., Exel, N. J. A. Van, Rutten, F. F. H., \& Brouwer, W. B. F. (2010). Willingness to Pay for a Quality-Adjusted Life-Year: The Individual Perspective. Value in Health, 13(8), 1046-1055. https://doi.org/10.1111/j.1524-4733.2010.00781.x

Bourne, R. (2019). 'Market failure' arguments are a poor guide to policy. Economic Affairs, 39(2), 170-183. https://doi.org/10.1111/ecaf.12346

CARLSSON, F., \&JOHANSSON-STENMAN, O. (2000). Willingness to pay for improved air quality in Sweden. Applied Economics, 32, 661-669. Retrieved from http://www.tandf.co.uk/journals/tf/00036846.html

Centemeri, L. (2019). Environmental Damage as Negative Externality: Uncertainty , Moral Complexity and the Limits of the Market. E-Cadernos CES [Online], 5(September 2009), 21-40. https://doi.org/10.4000/eces.266

Desvousges, W., Mathews, K., \& Train, K. (2012). Adequate responsiveness to scope in contingent valuation tr. Ecological Economics, 84, 121-128. https://doi.org/10.1016/j.ecolecon.2012.10.003

Ferronato, N., \& Torretta, V. (2019). Waste Mismanagement in Developing Countries: A Review of Global Issues. Int. J. Environ. Res. Public Health, 16, 1-28. https://doi.org/10.3390/ijerph16061060

Gillingham, K. (2011). Market failure and the structure of externalities. Harnessing Renewable Energy in Electric Power Systems: Theory, Practice, Policy, 69-92. https://doi.org/10.4324/9781936331864

Gujarati, D. N. (2003). BASIC ECONOMETRICS. Gary Burke.

Handayani, T., Chalid, N., \& Iyan, R. Y. (2015). ANALISIS KESEDIAAN MEMBAYAR IURAN KEBERSIHAN TERHADAP KEPUASAN MASYARAKAT DI LINGKUNGAN KELURAHAN LABUHBARU BARAT. JOM FEKON, 2(1), 1-14.

Hoevenagel, R. (1996). The validity of the contingent valuation method: Perfect and regular embedding. Environmental and Resource Economics, 7(1), 57-78. https://doi.org/10.1007/BF00420427

Human, M. O. H. R. D. (2019). Waste Management Principles and Practices (First Edit; D. W. G. P. Kumar, D. K. N. Rekha, \& M. V Anasuya, eds.). Hyderabad: Mahatma Gandhi National Council of Rural Education (MGNCRE), Hyderabad.

Liebowitz, S. . J., \& Margolis, S. E. (1995). Are network externalities a new source of market failure? Research in Law and Economics, 1-21. Retrieved from http://www.utdallas.edu/ liebowit/netwextn.html

Maghdalena, M., \& Widiastuti, D. (2014). ANALISIS KESEDIAAN MEMBAYAR (WTP) PROGRAM PENGELOLAAN SAMPAH DAN PELESTARIAN WADUK CIRATA - JAWA BARAT. Jurnal IImiah Agribisnis Dan Perikanan (Agrikan UMMU-Ternate), 6(3), 73-81.

Andrianto, A., Qurniati, R., \& Setiawan, A. (2016). PENGARUH KARAKTERISTIK RUMAH TANGGA TERHADAP TINGKAT KEMISKINAN MASYARAKAT SEKITAR MANGROVE. Jurnal Sylva Lestari, 4(3), 107-113.

Malinauskaite, J., Jouhara, H., Czajczynska, D., Stanchev, P., Katsou, E., Rostkowski, P., ... Spencer, N. (2017). Municipal solid waste management and waste-to-energy in the context of a circular economy and energy recycling in Europe. Energy, 141, 2013-2044. https://doi.org/10.1016/j.energy.2017.11.128

Nizar, M., Munir, E., \& Munawar, E. (2013). Manajemen Pengelolaan Sampah Kota Berdasarkan Konsep Zero Waste : Studi Literatur.

OECD. (2008). Household Behaviour and the Environment Reviewing the Evidence. France, Paris: ORGANISATION FOR ECONOMIC CO-OPERATION AND DEVELOPMENT.

Saez, E. (2013). Externalities: Problems and Solutions. 
Smith, C. (2008). Externality-correcting taxes and regulation.

Weimer, David L., Aidan R. Vining. 2017. Policy Analysis: Concepts and Practice. Sixth edition. Routledge. New York

Yang, F., Ding, L., Liu, C., Xu, L., \& Nicholas, S. (2018). Haze Attitudes and the Willingness to Pay for Haze Improvement : Evidence from Four Cities in Shandong Province, China. Int. J. Environ. Res. Public Health, 15(2297), 1-15. https://doi.org/10.3390/ijerph15102297

Yoada, R. M., Chirawurah, D., \& Adongo, P. B. (2014). Domestic waste disposal practice and perceptions of private sector waste management in urban Accra. BMC Public Health, 14(1), 1-10. https://doi.org/10.1186/1471-2458-14-697

Ziolo, M., Filipiak, B. Z., Iwona, B., Cheba, K., Tîrca, D. M., \& Novo-corti, I. (2019). Finance,

Sustainability and Negative Externalities . An Overview of the European Context. Sustainability, 11(4249), 1-35. https://doi.org/10.3390/su11154249 